COMUNICAÇÃO CIENTÍFICA

\title{
DIVERSIDADE GENÉTICA ENTRE PROGÊNIES E MATRIZES DE RAMBUTAN ${ }^{1}$
}

\author{
RENATA APARECIDA DE ANDRADE ${ }^{2}$, ESTER WICKERT ${ }^{3}$, \\ ANTONIO BALDO GERALDO MARTINS ${ }^{4}$, ELIANA GERTRUDES DE MACEDO LEMOS 5
}

RESUMO - O rambutan é uma frutífera exótica que apresenta alto potencial de mercado, e suas mudas podem ser obtidas por sementes ou vegetativamente. A produção de mudas via sementes é rotineiramente feita no Estado de São Paulo, tendo-se alta variabilidade no pomar, além de demorar mais tempo para entrar em produção. Embora caracteres morfológicos sejam amplamente usados na diferenciação de variedades, as técnicas moleculares permitem a comparação e a identificação genética dos materiais. Diante disso, o presente trabalho foi realizado, comparando progênies e plantas-matrizes de rambutan, por fAFLP. As análises foram realizadas no Laboratório de Bioquímica de Microrganismos e Plantas, do Departamento de Tecnologia - Faculdade de Ciências Agrárias e Veterinárias - UNESP - Câmpus de Jaboticabal-SP, utilizando 06 plantas de rambutan, denominadas: A; B; C; D; E e F. Foram coletadas folhas de 15 plântulas oriundas de cada planta-matriz e realizou-se a extração de DNA, sendo as amostras quantificadas em biofotômetro, e os marcadores fAFLP, obtidos de acordo com o protocolo AFLP Plant Mapping Protocol (Applied Biosystems), utilizando as combinações de pares de primers: ACG/CAC; ACT/CAT; ACA/CTT e ACC/CTT. Pode ser concluído que o uso de marcadores moleculares é eficiente na distinção de materiais e na obtenção de distância genética; não é recomendada a obtenção de mudas via sementes quando a finalidade é a de instalação de pomar comercial.

Termos para indexação: Nephelium lappaceum; fAFLP; polimorfismo.

\section{GENETIC DIVERSITY AMONG STOCK PLANTS AND PROGENIES OF RAMBUTAN}

\begin{abstract}
The rambutan is an exotic fruit that has a high market potential and the seedlings can be obtained by seed or vegetative. The production of seedlings by seed is routinely done in the state of São Paulo, having a high variability in the orchard, and take longer time to go into production. Although morphological characters are widely used in differentiation of the varieties, molecular techniques allow the comparison and identification of genetic material. Thus, the present research was realized, comparing rambutan stock plants and their progenies, by fAFLP. Analyses were realized at the Laboratory of Biochemistry of Microorganisms and Plants, Department of Technology - Faculdade de Ciências Agrárias e Veterinárias - UNESP - Jaboticabal/ SP, using 06 plants of rambutan, denomined: A, B, C, D, E and F. Were collected leaves of 15 seedlings derived from each stock plant and was done the DNA extraction, being the samples quantified according to AFLP Plant Mapping Protocol (Applied Biosystems), using combinations of pairs primers: ACG / CAC, ACT / CAT, ACA / CTT and ACC / CTT. Can be concluded that the use of molecular markers is effective to distinguish the materials and to obtain the genetic distance; is not recommended to obtain seedlings by seed when the purpose is to install a commercial orchard.
\end{abstract}

Index terms: Nephelium lappaceum; fAFLP; polymorphism.

\footnotetext{
${ }^{1}$ (Trabalho 203-11). Recebido em: 08-08-2011. Aceito para publicação em: 21-12-2011.Executado com auxílio financeiro e bolsa de pós-doutoramento da FAPESP.

${ }^{2}$ Eng. Agr., Prof. Assist. Dr., Departamento de Produção Vegetal, UNESP/FCAV - Câmpus de Jaboticabal. Via de Acesso Prof. Dr. Paulo Donato Castellane, s/n, CEP 14884-900, Jaboticabal-SP. e-mail: reandrad@fcav.unesp.br.

${ }^{3}$ Eng. Agr., Dra. Pesquisadora - EPAGRI, Itajaí-SC, e-mail: ewickert@terra.com.br.

${ }^{4}$ Eng. Agr., Prof. Assist. Dr., Departamento de Produção Vegetal, UNESP/FCAV, e-mail: baldo@fcav.unesp.br.

${ }^{5}$ Bióloga, Prof. Titular, Departamento de Tecnologia, UNESP/FCAV, e-mail: egerle@fcav.unesp.br
} 
O rambutan (Nephelium lappaceum L.) encontra-se entre as frutíferas exóticas com alto potencial de mercado, sendo consumido principalmente na forma in natura. O maior produtor brasileiro é o Estado da Bahia (região de Itabuna/Ilhéus) e o maior mercado consumidor São Paulo, o que tem levado alguns produtores paulistas a instalar a cultura por mudas originadas de sementes e sem informações sobre a resposta regional da planta. O Estado de São Paulo fornece frutos para comercialização de setembro a abril, período em que não há frutos oriundos da Bahia, o que ressalta o potencial paulista para o desenvolvimento da cultura (CEAGESP, 2008).

Os métodos de propagação possíveis, de acordo com a literatura, utilizados para o rambutan são: sementes, enxertia e alporquia. A propagação por sementes é relativamente fácil, porém as plantas entram em produção cerca de 8 a 10 anos após o plantio, além da variabilidade, enquanto as plantas oriundas de propagação vegetativa produzem em 3 a 4 anos e formam pomares uniformes (TINDALL, 1994; MELETTI;TEIXEIRA, 2000).

Há uma considerável diversidade genética no rambutan, existindo variação no formato da árvore e crescimento, coloração e tamanho das folhas, tipo de flor e número por panícula, coloração do arilo, textura, Brix, acidez, aderência à semente, tamanho e forma da semente, suscetibilidade a pragas e doenças, e tolerância ao frio e à seca (TINDALL, 1994). Os tipos cultivados são basicamente diferenciados pela coloração dos frutos, que varia de vermelho a amarelo, como também pela densidade e qualidade do arilo.

Os marcadores morfológicos são muito utilizados em estudos de genética e evolução, podendo utilizar diferentes caracteres, porém o efeito do ambiente e a ação gênica são fatores que podem complicar a avaliação. No entanto, descritores morfológicos têm sido usados por diversos pesquisadores para a caracterização de germoplasma (RODRIGUES, 2003). Embora existam técnicas mais avançadas, os descritores são mais acessíveis e antecedem outras técnicas, permitindo a orientação do trabalho a ser realizado com descritores mais sofisticados, como os marcadores moleculares (RITSCHEL et al., 1998), que são utilizados com o objetivo de avaliar relações genéticas entre cultivares, espécies e híbridos intra e interespecíficos, além de serem usados na construção de mapas genéticos (FERREIRA; GRATTAPAGLIA, 1995).

Dentre os marcadores moleculares de DNA mais usados atualmente, pode-se destacar o polimorfismo de comprimento de fragmentos de restrição (RFLP), DNA polimórfico amplificado ao acaso (RAPD), polimorfismo de comprimento de fragmen- tos amplificados (AFLP), minissatélites (VNTR) e microssatélites (KARP et al., 1996).

Os marcadores AFLP (Amplified Fragment Length Polymorphisms) combinam técnicas de RFLP (Restriction Fragment Length Polymorphisms) e de PCR (Polymerase Chain Reaction), são de caráter dominante, revelando altos níveis de polimorfismo com grande número de marcadores e atuando com precisão em análises de germoplasma. Possuem vantagens em relação às outras técnicas, tais como $\mathrm{o}$ alto nível de polimorfismos identificáveis e a alta reprodutibilidade da técnica (YANG et al., 2005). Na técnica AFLP, os iniciadores utilizados nas reações de PCR são marcados com fluorocromos e o produto da reação é identificado por separação eletroforética em géis de poliacrilamida ou através de capilares de vidro contendo uma matriz, e a detecção de fluorescência é realizada através de laser permitindo a análise por softwares desenvolvidos especificamente para tal (WEISING et al., 2005).

Em pomares comerciais, é desejável a utilização de plantas uniformes, o que se consegue através da propagação vegetativa, originando clones. Como a maioria dos cultivos no Estado de São Paulo tem sido realizada utilizando-se de sementes, o presente trabalho objetiva comparar progênies com suas respectivas matrizes, utilizando fAFLP, refletindo a identidade genética de cada material.

As análises foram realizadas no Laboratório de Bioquímica de Microrganismos e Plantas, do Departamento de Tecnologia - Faculdade de Ciências Agrárias e Veterinárias - UNESP - Câmpus de Jaboticabal-SP, utilizando 06 plantas de rambutan, denominadas: A; B; C; D; E e F. De cada planta, foi coletado material para a análise com marcador molecular (fAFLP), visando à comparação entre a progênie e sua planta-matriz. Coletaram-se frutos de plantas de pomar comercial, de polinização aberta, sendo extraídas as sementes e colocadas para germinar em canteiros de areia (condições de ripado $-50 \%$ de luminosidade). Após a emergência, foram coletadas folhas de 15 plântulas oriundas de cada planta-matriz e realizou-se a extração de DNA, segundo Ferreira e Grattapaglia (1998), sendo as amostras quantificadas em biofotômetro, de acordo com Sambrook et al. (1989). Os marcadores fAFLP foram obtidos de acordo com o protocolo AFLP Plant Mapping Protocol (Applied Biosystems) 1997, utilizando-se de combinações de pares de primers: ACG/CAC (Joe - fluorescência de coloração verde); ACT/CAT (Fam - fluorescência de coloração azul); ACA/CTT (Fam); e ACC/CTT (Ned - fluorescência de coloração amarela). Para análise, foram selecionados marcadores com tamanho entre 50 e 500 pares 
de bases e utilizados os softwares GeneScan (ABI Prism versão 1.0) e Genotyper (ABI Prism versão 1.03) para a coleta dos dados e a construção de matriz binária, que foi convertida em matriz de distância com auxílio do software Paup [4.0b10], construindo-se então o dendrograma para a visualização das relações genéticas entre as plantas. O dendrograma foi construído pelo método da Distância e algoritmo UPGMA (Unweighted Pair Group Method Using Arithmetic Average), pelo software Mega 3.1 - Molecular Evolutionary Genetics Analysis (KUMAR et al., 2004).

A análise dos marcadores permitiu a obtenção dos dendrogramas exibidos na Figura 01, onde é possível verificar-se:

Matriz A: variabilidade entre os materiais, formando-se dois grupos, sendo que a matriz diferenciou-se totalmente da progênie. À exceção da planta 1 , todas as outras formaram um único grupo. As plantas da progênie apresentaram distância genética entre si de cerca de 0.23 e de 0.30 em relação à matriz.

Matriz B: formação de dois grupos, sendo um composto pelas plantas 14 e 15 e o outro pelas demais, incluindo a planta-matriz, que está mais próxima da planta 8 . Verifica-se distância genética alta (aproximadamente 0.22).

Matriz C: divisão das plantas em dois grandes grupos, sendo um deles formado pelas plantas 3 e 6 da progênie, e o outro grupo pelas demais, incluindo a planta-matriz. Nota-se distância genética máxima maior que 0.25 . No caso deste material, diferente do observado até o momento para os demais analisados, verifica-se a ocorrência de duas plantas idênticas na progênie (plantas 7 e 10), bem próximas à planta-matriz (distância genética inferior a 0.05), o que seria desejável na instalação de pomares. Entretanto, como ocorreu com apenas duas plantas, não se recomenda a propagação deste material por sementes.

Matriz D: formação de dois grandes grupos, sendo um composto por apenas uma planta da progênie (planta 11) e o outro formado pelas demais e dividido em vários subgrupos, estando a planta-matriz sozinha. Observa-se distância genética máxima de cerca de 0.25 ;

Matriz E: as plantas 11 e 14 da progênie apresentam grande divergência em relação às demais e também em relação à matriz (distância de cerca de 0.18 e 0.32 , respectivamente). A planta-matriz mostrou maior similaridade com um grupo de plantas da progênie, com menor distância genética em relação à planta 4. Embora também seja possível sugerir que tenha ocorrido recombinação genética, os materiais desta planta de rambutan também não poderiam ser propagados por semente, uma vez que, embora a planta-matriz tenha grande similaridade com as plantas $2 ; 3 ; 4 ; 5 ; 10$ e 13 da progênie, não seria possível separar estas sementes das demais (com maior distância genética) visualmente.

Matriz F: formação de dois grandes grupos, sendo um deles formado pelas plantas 1 e 9 , e o outro, com vários subgrupos, composto pelas demais, incluindo a planta-matriz, que aparece sozinha. Nota-se distância genética máxima alta (cerca de 0.22 ), estando a maioria dos materiais a, pelo menos, 0.10 . Dessa forma, este material também não deve ser propagado por sementes, pois há variabilidade entre planta-matriz e progênie, além de variabilidade entre as plantas da progênie.

A existência de variabilidade entre materiais também foi verificada por Carvalho (1998) e Salla et al. (2002), que, respectivamente, observaram alta segregação genética em pomares de acerola onde as mudas são obtidas por sementes e que o polimorfismo gerado com marcadores de DNA evidenciam que, apesar da base genética estreita, que caracteriza as coleções de acerola encontradas no Brasil, a variabilidade é relativamente alta. Técnicas moleculares são muito usadas e com bons resultados na caracterização e identificação de polimorfismo de materiais. O uso de RAPD, por exemplo, mostrou-se eficiente na caracterização dos genótipos de butiazeiros, permitindo identificar grande variabilidade genética, disponibilizando dados para seleção e conservação de material genético, para futuros trabalhos de melhoramento (NUNES et al., 2008). Marcadores moleculares também foram utilizados com sucesso na obtenção de dissimilaridade entre materiais por Shah et al. (1994), Sawazaki et al. (1998), Souza et al. (2001), Lima et al. (2003) e Bianchi et al. (2003), em trabalhos com dendê, palmeira, pupunha, pêssego e ameixa, respectivamente.

Pode-se concluir que o uso de marcadores moleculares é eficiente na distinção de materiais e na obtenção de distância genética; não é recomendada a obtenção de mudas via sementes quando a finalidade é a de instalação de pomar comercial. 

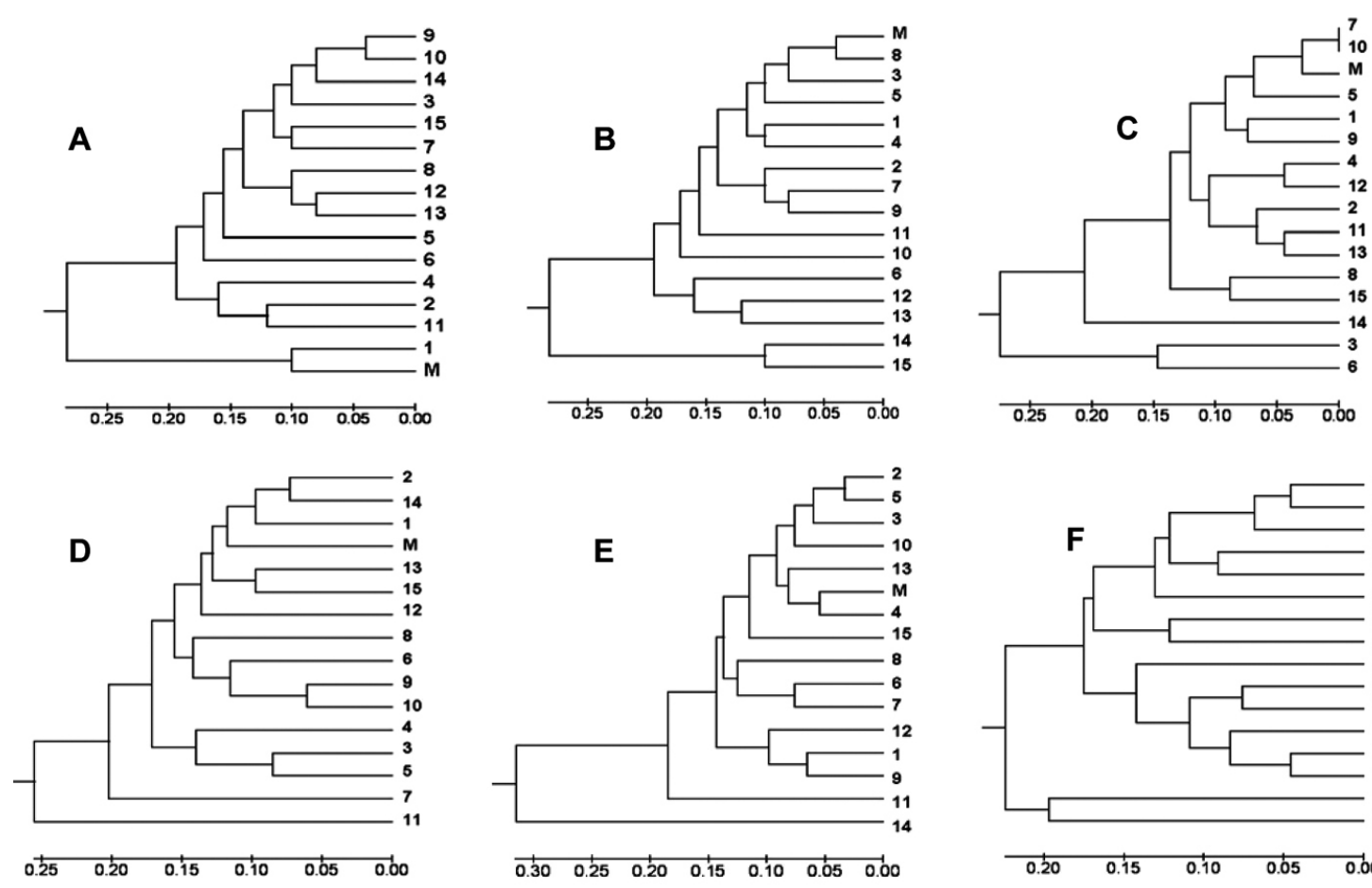

FIGURA 1 - Dendrogramas obtidos por fAFLP para comparação entre as plantas-matrizes de rambutan e suas progênies, onde $\mathrm{M}$ = planta matriz e 1 a 15 = progênie. (UPGMA).

\section{AGRADECIMENTOS}

À FAPESP, pela concessão de bolsa de pós-doutoramento (Processo 05/58114-5) e auxílio pesquisa (Processo 06/57102-6).

\section{REFERÊNCIAS}

AFLP. Plant mapping protocol applied biosystems. 1997. $45 \mathrm{p}$.

BIANCHI, V.J.; FACHINELLO, J.C.; SCHUCH, M.W. RAPDs na caracterização genético-molecular e no estudo da variabilidade genética de cultivares de ameixeira. Revista Brasileira de Fruticultura, Jaboticabal, v.25, n.2, p.272-274, 2003.

CARVALHO, R. I. N. Variabilidade em plantas jovens de aceroleira propagadas por semente. Agropecuária Catarinense, Florianópolis, v.11, n. 1, p. 16-18. 1998.
CEAGESP - Companhia de Entrepostos e Armazéns Gerais de São Paulo. Sistema de Informação de Mercado, São Paulo: Seção de Economia e Desenvolvimento, 2008.

FERREIRA. M.E.; GRATTAPAGLIA, D. Introdução ao uso de marcadores moleculares em análise genética. 3.ed. Brasília: EMBRAPA-CENARGEN, 1998. 220p.

KARP, A.; SEBERG, BUIATTI, M. Molecular techniques in the assessment of botanical diversity. Annals of Botany, Oxford, v.78, n.2, p.143-149, 1996.

KUMAR, S.; TAMURA, K.; AND NEI, M. MEGA3: Integrated software for Molecular Evolutionary Genetics Analysis and sequence alignment. Briefings in Bioinformatics, Oxford, n.5, p.150-163, 2004.

LIMA, M.R.; AUGUSTIN, E.; CHOER, E.; RASEIRA M.C.B. Caracterização de cultivares de pessegueiro e nectarineira por marcadores moleculares. Pesquisa Agropecuária Brasileira, Brasília, v. 38, n. 3, p. 349-355, 2003. 
MELETTI, L.M.M.; TEIXEIRA, L.A.J. Propagação de plantas. In: MELETTI, L.M.M.. (Org.). Propagação de frutíferas tropicais. Guaíba: Editora Agropecuária, 2000. p.13-49.

NUNES, A.M.; BIANCHI, V.J.; FACHINELLO, J.C.; CARVALHO, A.Z.; CARDOSO, G. Caracterização molecular de butiazeiro por marcadores RAPD. Revista Brasileira de Fruticultura, Jaboticabal, v.30, n.3, p.702-707, 2008

RITSCHEL, P.S.; THOMAZELLI, L.F.; HUAMÁN, Z. Caracterização morfológica do germoplasma de batata-doce mantido pela EPAGRI. 1998. Disponível em: <http://www.cnph.embrapa.br/pa/pa16. html>. Acesso em: 06 fev. 2011.

RODRIGUES, K.A.M. Variabilidade genética do trigo. 2003. Disponível em: <http://www.ufv.br/dgb/ bioano01/div33.html>. Acesso em: 14 fev.2011.

SALLA, M.F.S.; RUAS, C.F.; RUAS, P.M.; CARPENTIERI-PÍPOLO, V. Uso de marcadores moleculares na análise da variabilidade genética em acerola (Malpighia emarginata D.C.). Revista Brasileira de Fruticultura, Jaboticabal, v.24, n.1, p.15-22, 2002.

SAMBROOK, L.; FRITCH, E.F.; MANIATIS, T. Molecular cloning: a laboratory manual. Cold Spring Harbor: Cold Spring Harbor Laboratory, 1989.
SAWAZAKI, H. E.; BOVI, M. L. A.; SODEK, L. Genetic relationships of palms based on enzimatic and RAPD polymorphism. Revista Brasileira de Biologia, São Carlos, v.58, n.4, p.681-691, 1998.

SHAH, F. H.; RASHID, O.; SIMONS, A. J.; DUNSDON, A. The utility of RAPD markers for the determination of genetic variation in oil palm (Elaeis guineensis). Theoretical and Applied Genetics, New York, v.89, p. 713-718, 1994.

SOUZA, N.R.; RODRIGUES, D.P.; CLEMENT, C.R.; NAGAO, E.O.; ASTOLFI-FILHO, S. 2001. Discriminação de raças primitivas de pupunha (Bactris gasipaes) na Amazônia brasileira por meio de marcadores moleculares (RAPDS). Acta Amazonica, Manaus, v.31, n.4, p.539-545, 2001.

TINDALL, H.D. Rambutan cultivation. Rome: FAO, 1994. 163p. (Plant Production and Protection Paper, 121)

YANG, C.; ZHANG, J.; XU, Q.; XIONG, C.; BAO, M. Establishment of AFLP technique and assessment of primer combinations for mei flower. Plant Molecular Biology Reporter, New York, v. 3, p.790-791, 2005.

WEISING, K.; NYBON, H.; WOLFF, K.; KAHL, G. DNA fingerprint in plants: principles, methods and aplications. $2^{\text {nd }}$. Boca Raton: CRC Press Taylor e Francis Group, 2005. 444p. 